\title{
Performance of Schiff Bases Metal Complexes and their Ligand in Biological Activity: A Review
}

\author{
Farah M. Ibrahim ${ }^{1}$ and Saifaldeen M. Abdalhadi ${ }^{2, *}$ \\ ${ }^{1}$ Department of Chemistry, College of Science, Al-Nahrain University, Baghdad, Iraq \\ ${ }^{2}$ Department of Remote Sensing, College of Remote Sensing and Geophysics, \\ $\mathrm{Al}$-Karkh University of Science, Baghdad, Iraq
}

\begin{tabular}{ll}
\hline \multicolumn{1}{c}{ Article's Information } & \multicolumn{1}{c}{ Abstract } \\
\hline Received: & Schiff bases are a broad class synthesized compound, which is prepared for the \\
16.10 .2020 & condensation process between the primary amine group and an aldehyde or \\
Accepted: & ketone group. Schiff base metal complexes play an important role in many \\
20.12 .2020 & applications such as biological activity, catalytic activity, and optical property. \\
Published: & The wide range application of Schiff base metal complexes came from the \\
13.03 .2021 & versatility of Schiff base reactions with many different transition metals. This \\
Keywords: & flexibility of the reactions was given these complexes, many different properties \\
Schiff base & and uses in a biological human system such as antibacterial, antifungal, \\
Schiff base metal complex & anticancer, antimalarial, and others. This review gives many examples of Schiff \\
Human system & bases, metal complexes, and there ligands with biological applications in the \\
Biological activity & human system. \\
Antibacterial & \\
Antifungal &
\end{tabular}

DOI: 10.22401/ANJS.24.1.01

*Corresponding author: dr.saifaldeen@kus.edu.iq

\section{Introduction}

Schiff base reaction was investigated by Hugo Schiff from last 155 years ago, and these compounds are still having attention from scientists and researchers due to their applications in different fields. Schiff base compounds are prepared from the reaction of a primary amine with the carbonyl group of aldehyde $(\mathrm{RHC}=\mathrm{O})$ or ketone $\left(\mathrm{R}_{2} \mathrm{C}=\mathrm{O}\right)$, Figure 1. Schiff bases have a functional group carbonnitrogen double bond $(-\mathrm{C}=\mathrm{N}-)$ called azomethine or imine, this imine group is very important for complex reaction and gives an important application in biological activity [1-4].

The Schiff base mechanism is nucleophilic addition reaction throw the carbonyl group $(\mathrm{C}=\mathrm{O})$. The nucleophile is the primary amine which is reacts with the aliphatic or aromatic aldehyde or ketone to give an intermediate compound called carbinolamine. This intermediate compound was loses water molecule by hydrolyses process with acidic or basic media as a catalyst [5].

Schiff bases metal complex are widely used in medicine for treating multiple viral diseases due to their transition metal complexes, which is play a key role in several areas, including, antibacterial, antifungal, anticancer, and anti-inflammatory [6-8], as well as these organometallic materials, were used as a catalyst in many reactions such as Aldo reaction, polymerization reaction, oxidation reaction, and others [9-13]. Currently, Schiff base complexes have effective scavengers of reactive oxygen species, which is act as antioxidant compound. These compounds are decrease the free radicals in the human body, which is causes various disorders and diseases [14]. The metal ions are responsible for the operation of enzymes system in the human body. Many Schiff bases complexes were used to synthesis medication compounds and this is because the reactive interacting of the Schiff base ligand with the metal ion and become more effective if compared with the free metal Schiff bases [1517]. The objective of this paper is the present of biological activity of the Schiff base complexes and ligand against the bacterial and fungal.

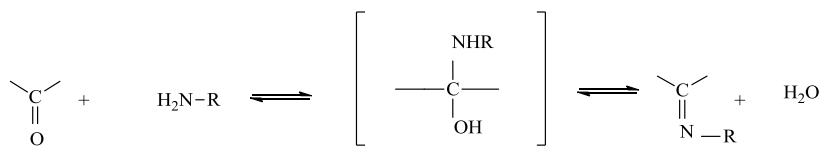

Figure 1. Scheme of preparation of Schiff base compound [18].

\section{Schiff Base Metal Complexes}

In 2009, Al-Masoudi N. and co-workers synthesized a metal complexes of 1, 2, 4-triazole Schiff base which was given antiviral properties against human immunodeficiency virus (1) and human immunodeficiency virus (2). Tetrazolium based on MTT assay (Tetrazolium dye 3-(4,5-dimethylthiazol-2-yl)-2,5-diphenyltetrazolium 


\title{
Al-Nahrain Journal of Science
}

\author{
ANJS, Vol.24 (1), March, 2021, pp. 1-10
}

bromide) is a colorimetric ocean used to measure the activity of enzymes and to determine the cytotoxicity of the medical component or toxic substances [19], the assay was used the mammalian cell lines MT-4 cells for the detection of anti-HIV. Largest activity observed in complexes comparing with Schiff base ligand and especially with gold complex due to its highly antiviral property, the coordination occur through the sulfur atom and nitrogen of triazole ring with gold ion, Figure 2 [2021].

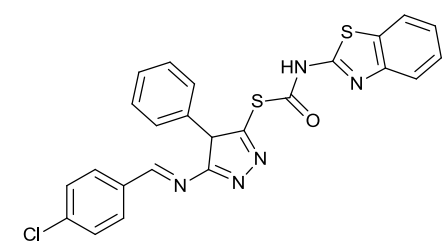

(1)

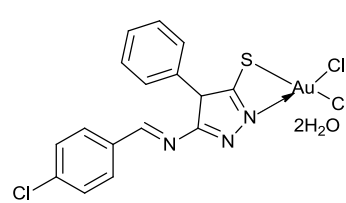

(2)
Figure 2. Structures of antiviral Schiff bases metal complexes.

In 2013, Laila H. and co-workers investigated the ion of $\mathrm{Fe}$ (II) with Schiff base amino acid chelates derived from the ortho-hydroxynaphth aldehyde with different amino acid (L-alanine, L-phenylalanine, L-aspartic acid, L-histidine and L-arginine).The Fe (II) complexes were synthesized and characterized via chemical and physical measurements, Figure 3. The complex has a nonelectrolytic behavior from conductivity measurements. The spectroscopic data was proposed that Schiff bases ligands shown tridentate coordinate with the ions of the metal and that by protonated phenolic, azomethine and carboxylate, while by using the L-histidine, here will found the tetradentate by deprotonated phenolic, azomethine, carboxylate and nitrogen of imidazole ring and the structure of the complex has an octahedral geometry. The interaction between CT-DNA and the prepared Schiff base complexes were characterized by spectro-photometric and viscosity measurements. The Schiff base ligands and their complexes were screened for their antibacterial activity against Escherichia coli, Pseudomonas aeruginosa and Bacillus cereus also the antifungal activity was tested against Penicillium purpurogenium, Aspergillus flavus and Trichotheium rosium. The results were showed that the metal complexes are more reactive than Schiff base amino acid [22-23].
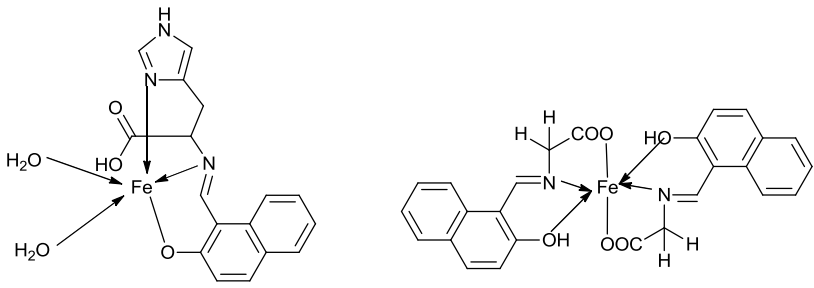

Figure 3. Schiff base amino acid ligands and their Fe (II) complexes.
In 2014, Sharma M. and co-worker investigated a new Schiff base compounds of hydrazine derivatives with different substitution group and all these derivatives were characterized by using physical and chemical analytical technique. These derivatives were used as antimalarial activity and there were compared with chloroquine, which is used as an antimalarial medication. These Schiff base derivatives exhibit a good antimalarial activity if it compared with chloroquine [24], Figure 4. Also, another Schiff bases derivative based on sulphonamide compound as a backbone for these derivatives, and all the derivatives have an antimalarial activity and used as a strong inhibitors for carbonic anhydrase enzyme, which is shown in Figure 5. This activity depends on the substituted groups in the aromatic aldehydes [20].<smiles>[R7]c1cccc(/C=N/NC(=O)C(=O)Nc2ccc(Nc3cccc4cc(Cl)ccc34)cc2)c1</smiles>

Figure 4. The structures of antimalarial hydrazine Schiff base ligand.

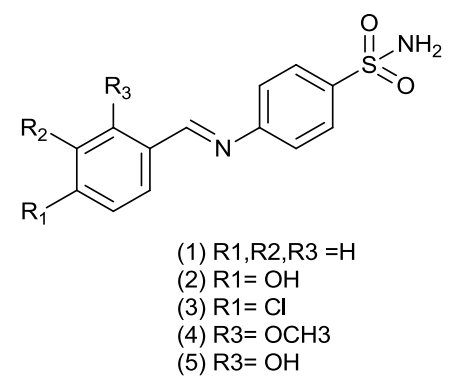

Figure 5. Sulphonamide derivatives Schiff bases ligands.

In 2015, Anjali J. and co-worker prepared different triazole Schiff base ligands and there complexes with Co (II), Ni (II), Ag (I) ions, and characterized using physical and analytical technique, Figure 6 . The Schiff base ligand was act as a chelate ligand. The octahedral structure was investigated in $\mathrm{Ni}$ (II) and $\mathrm{Cu}$ (II) complexes and the square planar structure was detected for the $\mathrm{Ag}$ (I) complex. All complexes showed more antibacterial activity against Micrococcus Proteus and Pseudomonas syringe if compared with the free Schiff bases ligand due to metallization of the Schiff base ligand. These complexes also exhibited good antifungal activity against strains Rhizopus stolonifer and Aspergillus niger [25]. 


\title{
Al-Nahrain Journal of Science
}

\author{
ANJS, Vol.24 (1), March, 2021, pp. 1-10
}

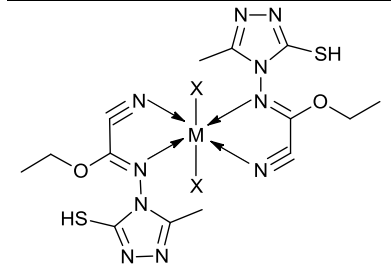

$\mathrm{M}: \mathrm{Ni}, \mathrm{Cu}, \mathrm{X}: \mathrm{C}$

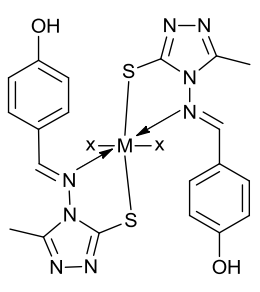

$\mathrm{M:} \mathrm{Ni,} \mathrm{Cu}, \mathrm{X:Cl}$

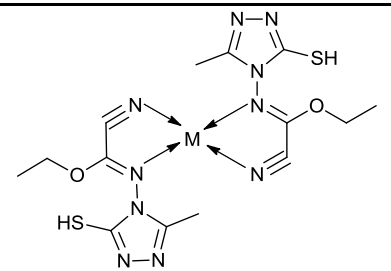

$\mathrm{M}: \mathrm{Ag}$

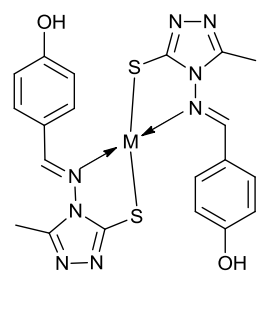

$\mathrm{M}: \mathrm{Ag}$

Figure 6. The structure of the complexes.

In the same year, Kulandaisamy A. and Palanimurugan A. prepared the new transition metal complexes of VO (II), Co (II), Ni (II), Cu (II), Zn (II) with mixed Schiff base ligand of benzylidene para-nitroaniline and 2,2-bipyridyl, All these compounds were characterized by spectroscopy technique analyses, so that all these complexes have a square planar geometry, except VO (II) complex has a square pyramidal geometry Figure 7 . The magnetic susceptibility and molar conductivity used to measure the monomeric structure and electrolytic behavior of the complexes. The cyclic voltammetry of the $\mathrm{Cu}$ (II) complex was recorded in acetonitrile solution and shows a quasireversible peak and their oxidation redaction properties were reported. The biological activity of the prepared compounds was tested against different types of bacteria such as Escherichia coli, Staphylococcus aureus, Bacillus subtilis, Salmonella typhi, and Klebsiella pneumonia. The antimicrobial activity was gave a good results for complexes, compared with the ligand, The Zn (II) complex has a great antimicrobial activity than all other complexes due to greater lipophilicity [26].

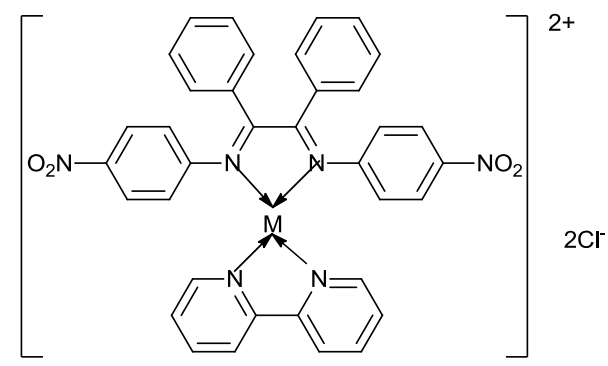

Where, $\mathrm{M}=\mathrm{Cu}(\mathrm{II}), \mathrm{Ni}(\mathrm{II}), \mathrm{VO}(\mathrm{II})$ and $\mathrm{Zn}(\mathrm{II})$

Figure 7. The geometry of mixed Schiff base ligand complexes.

In the same year, Hasan Md.R and co-workers prepared the Ni (II) complexes of Schiff bases ligand from

mono/di-ketone with anthranilic acid and there complex was characterized by $\mathrm{H}^{1}$ NMR, mass spectroscopy electronic spectra, and others. Four coordinates structure was proposed for the nickel (II) complex, Figure 8. The stoichiometry of $\mathrm{Ni}$ (II) complex was showed a mole ratio $1: 1$ to (M:L). The efficacy of antifungal for the Ni (II) complex has been screened against the growth of different types of fungi such as Alternaria alternate, Carvularia lunatic and Fusarium equiseta as well as the efficiency of the complex was tested as antibacterial aganist Vibrio cholera, Salmonella typhi, Shigella dysentery, Bacillus cereus and Escherichia coliin and evaluate their antimicrobial effect and gave a good result in growth inhibition [27].

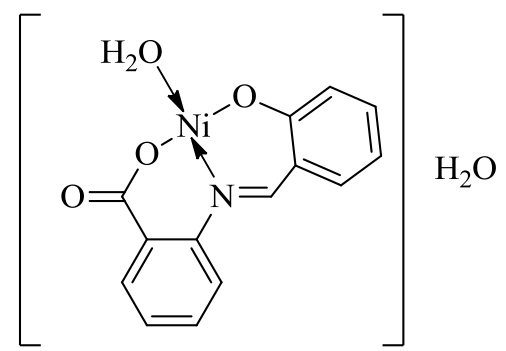

Figure 8. Geometry of Ni (II) complexes of Schiff bases.

In the same year, Mustafa Y. and co-workers prepared a new Schiff base derivative which is based on salicylaldehyde with the aniline substituted. The ligand was synthesized and characterized by spectroscopic analyses and X-ray single crystal diffraction, Figure 9. Theoretical calculations were optimized the molecular structure and calculated the energy gap of the Schiff base ligand which is found that the theoretical calculations have a good match with the experimental results. The density functional theory (DFT) method was used to calculate the energy gab and optimized geometry of the suggested compound. From spectroscopy and computational data there was found the intermolecular interaction between enol and imine group and that was gave the stability of the compounds. Also there was atautomeric stability between the same groups of compound. This compound was gave a good activity against many types of bacteria and fungi such as Bacillus subtilis, Saphylococcus aureus, Escherichia coli, Enterococcus faecalis, Pseudomonas aeruginosa, Escherichia coli, Bacillus cereus, Proteus vulgaris, Candida albicans and Candida tropicalis [28].

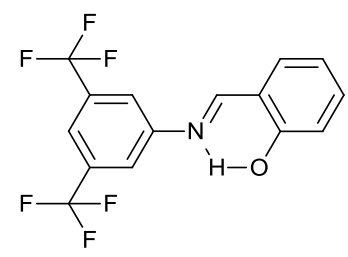

Figure 9. Chemical structure of Schiff base 3,5bis(triflouromethyl)aniline and salicylaldehyde.

In 2017, Elena P. and co-workers reported the synthesis of new Schiff base ligands (hydrazone 


\title{
Al-Nahrain Journal of Science
}

\author{
ANJS, Vol.24 (1), March, 2021, pp. 1-10
}

derivative) which are characterized by different physical and chemical techniques, Figure 10. The new ligand was reacted with different types of metals such as $\mathrm{Cu}$ (II), $\mathrm{Pt}$ (II) and Ni (II) by direct reaction between metal ion and ligand solution by using a molar ratio of $1: 1$ (M:L). The spectroscopic data showed that the new compound was coordinate as a tridentate ligand in positions of phenolate nitrogen, azomethine, and keto oxygen atoms. The anticancer and antimicrobial activity were studied by all these complexes, and compared with the ligand by using the paper disc diffusion method and serial dilutions in the liquid broth method. All complexes and ligand were showed as a good antimicrobial activity against Candida Albicans and Staphylococcus aureus (Gram-positive), as well as the complexes, exhibited a good antitumor agent against breast cancer cells [29].

$$
\begin{aligned}
& \underbrace{1}_{0} \\
& \mathrm{M}=\mathrm{Cu}, \mathrm{X}=\mathrm{C} \\
& \mathrm{M}=\mathrm{Ni}, \mathrm{Pt}, \mathrm{X}=\mathrm{Cl}
\end{aligned}
$$

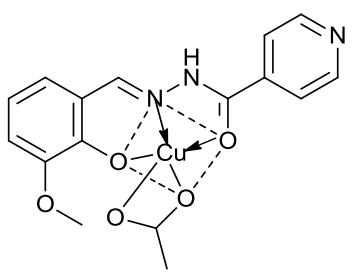

Figure 10. The structure of the hydrazonemetal complexes.

In the same year, Kareem. M. and Salman. H. Synthesized the transition metal complexes of Ni (II) and $\mathrm{Cu}$ (II) from the azo ligand derived which prepared from 4-amino antipyrine. The ligand (Figure 11) and there complexes were characterized by electronic measurement such as infrared spectroscopy, UV-Vis and others. The suggest geometry of these complexes was octahedral structure. The complexes of 4-amino antipyrine derivatives with transition metal have the anti-cancer activity and antimicrobial properties. Also, the azo compound and their complexes have a biological activity with pharmaceutical and analytical application such as antimicrobial, antiinflammatory, antiparasitic activity, antifungal, antibiotics and antiulcer drug. The biological activity of metal complexes derivative of 4-amino antipyrine was tested against gram-positive bacteria (Streptococcus pyogenes and Staphylococcus aureus), and gram-negative bacteria (Escherichia coli, Proteus mirabilis, Klebsiella pneumonia, Salmonella typhi, Vibrio and Acinetobacterbaumannii) and the metal complex was gave a good result as an antibacterial activity [30].

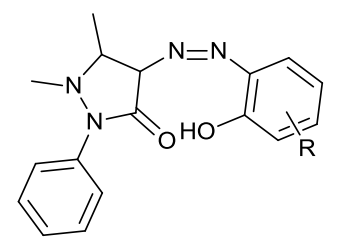

Figure 11. The structure of antipyrine ligand.
In same year, Reiss A. co-workers synthesized three complexes of $\mathrm{Co}$ (II), $\mathrm{Cu}$ (II) and $\mathrm{Ni}$ (II) with ceftazidime derivative ligand. The structures of complexes were characterized by spectroscopic analysis Figure 12. The SEM analysis was used to study the morphology of ligands and complexes. Theoretical calculations of these complexes were studied through the optimized molecular geometry. The high occupied molecular orbital (HOMO) and lowest unoccupied molecular orbital (LUMO) were predicted the active site for coordination. The Schiff base ligand was acting as bidentate chelating agent with metal ions through the phenolic and azomethine groups. The prepared complexes have a square planar geometry with non-electrolyte properties. Antimicrobial activity of complexes was measured through growth inhibition zone diameters against both Planktonic and biofilm embedded cells and all complexes were gave a good antimicrobial activity [31].

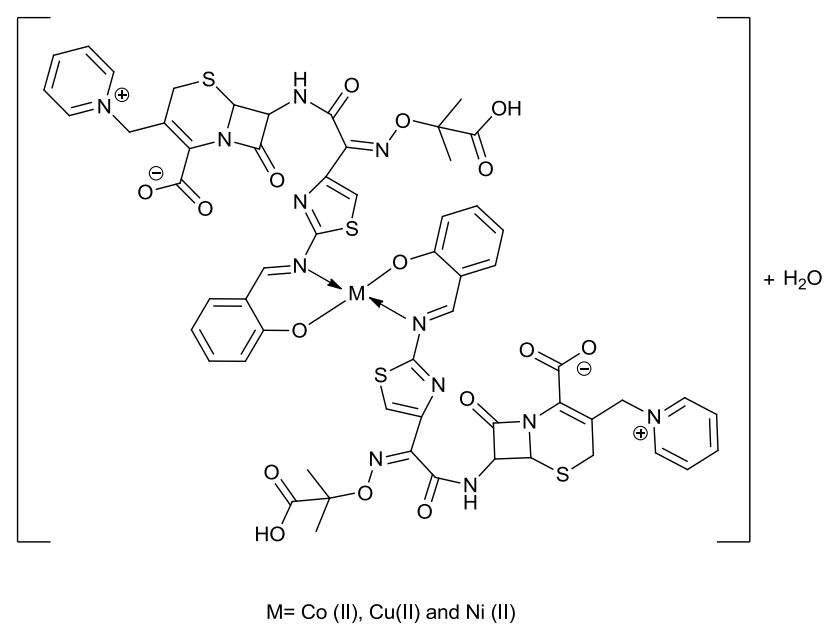

Figure 12. Ceftazidime derivative metal complexes $\left[\mathrm{ML}_{2}\right] \cdot \mathrm{H}_{2} \mathrm{O}$.

In 2018, Lin-Wei Z. and co-workers synthesized the new Schiff base metal complex (Tetraoxime) which is called bis-salamo, Figure13. This Schiff bases ligand and there complexes have a wide interest last few years because it used as a model sample to understand the structures of biological compounds and processes, the interaction of complexes with DNA and protein have an active field for understand the reactive models for protein with nucleic acid reactions, probes of DNA structure and many applications [19]. Tetraoxime compound was synthesized Schiff base reaction then reacted with divalent cobalt and zinc ions to form homometallic coordination complexes, these complexes characterized using fluorescent spectra, crystallographic analyses, and analytical spectroscopies so the square pyramidal, trigonal bipyramidal, and octahedral geometries were proposed for two metals with different ligands. The coordination of Co (II) and $\mathrm{Zn}$ (II) complexes poses a 3D supramolecular structure and OD dimer structure respectively via the intermolecular hydrogen bond. The fluorescence spectra of $\mathrm{Co}$ (II) and $\mathrm{Zn}$ (II) complexes indicate that the 


\title{
Al-Nahrain Journal of Science
}

\author{
ANJS, Vol.24 (1), March, 2021, pp. 1-10
}

fluorescence was lowered and it well be improved if compared with the free Tetraoxime Schiff base compound due to the increasing of conjugation system [32].

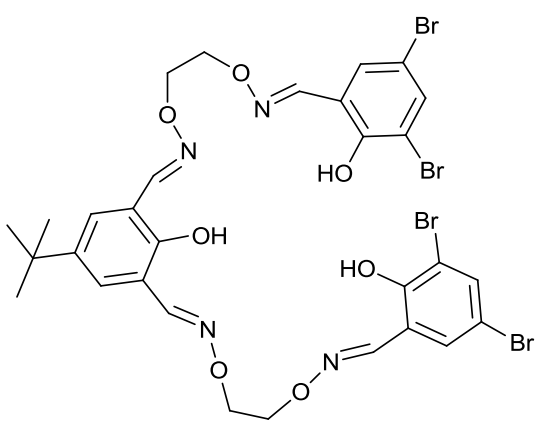

Figure 13. The bis (salamo), tetraoxime ligand.

In the same year, Nuray Y. and co-workers prepared a Schiff base from the reaction of 2-aminopyridine with 5chlorosalicylaldehyde. The structure of compound was investigated by spectroscopy and X-ray data Figure 14. The geometry of the Schiff base was confirmed by X-ray single-crystal data and which had a good agreement with the geometry that predicted by computational study using the density functional theory. The antimicrobial activity of the compound was tested against some bacteria such as Staphylococcus aureus, Enterococcus faecalis, Bacillus cereus NRRL, Escherichia coli ATCC 25922, E. Escherichia coli ATCC 35218 and Pseudomonas aeruginosa), and fungi such as Candida albicans and Candida tropicalis. The minimum inhibitory concentration was estimated by the broth micro dilution test. Furthermore, the Schiff base compound was interacted with calf thymus DNA through electrostatic binding and these studies characterized by UV.Vis spectroscopy. The colorimetric response of the Schiff base compound receptors was investigated by different addition of anions [33].

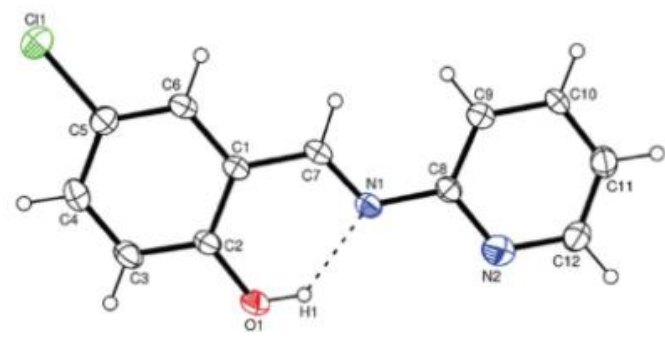

Figure 14. The structure of Schiff base ligand.

In the same year, de Fátima A. and coworker wrote a short review for anti-urease Schiff bases ligand and their transition metal complexes. Copper (II) complex with Schiff base hydrazone ligands have a urease inhibitor activity, $\mathrm{Cu}$ (II) ion in these complexes was polymerizing the protein by enhancement it and the mechanism will be preventing the formation of the thiol group, which is linking to histidine in the protein to form the ureolytic site. These complexes have different geometries such as tetrahedral, square planar, and octahedral, due to electronic configuration and the great Lewis acid behavior of copper ion, the coordination of these complexes occur by the nitrogen of the imine group, and the other donor atoms of Schiff base, Figure 15.

There is a new Schiff base ligand with oxovanadium complex was showed a future vision for urease inhibitor activity, Figure 16. Also there are two nickel (II) complexes with bidentate Schiff base ligand are important in medicinal chemistry, Figure 17. These complexes have square planar and octahedral geometries, and it was used to inhibit the ureolytic site in the protein [34].

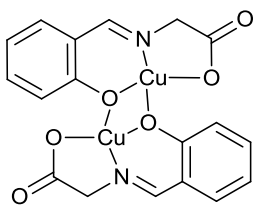

(1)<smiles></smiles>

(3)

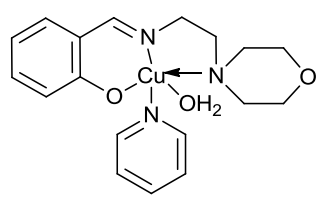

(2)

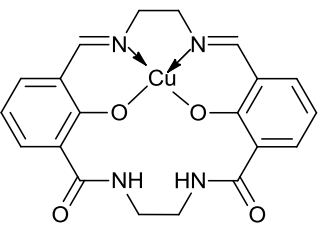

(4)
Figure 15. Urease inhibitors complexes.<smiles>CC(=O)NP1(O)(OC(N)=NN=Cc2cccc([N+](=O)[O-])c2)Oc2ccc(Br)cc21</smiles>

(1)

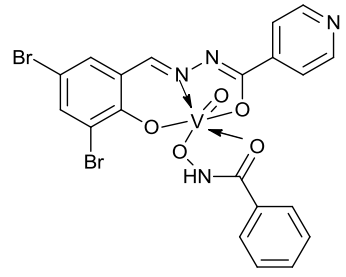

(2)
Figure 16. The structures of vanadium complexes.

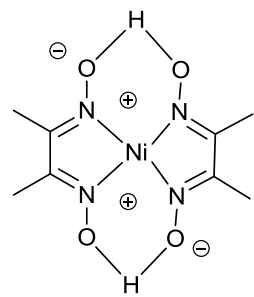

(1)

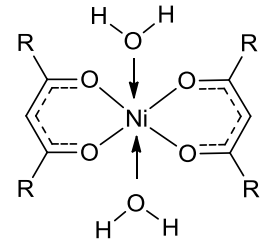

(2)
Figure 17. Four and six nickel coordination complexes.

In 2019, Abdelsalam M. and co-worker prepared the triazole Schiff base ligand and reacted with different types of metal ions such as $\mathrm{Cu}$ (II), Co (II), Ni (II), Zn (II) by using molar ratio 1:1 [ligand: metal] by microwave reaction technique, Figure 18. The geometry of the prepared complexes was characterized by chemical and physical with the thermal study. These complexes act as a bidentate and tridentate chelating agent, and the 


\title{
Al-Nahrain Journal of Science
}

\author{
ANJS, Vol.24 (1), March, 2021, pp. 1-10
}

coordinated occur through the imine $\mathrm{C}=\mathrm{N}$, oxygen of $-\mathrm{OH}$ group, and nitrogen of triazole ring with the metal ions. All complexes were tested as antimicrobial agent against different types of bacterias and funguses such as Escherichia Coli, Salmonella typhimurium, Bacillus subtilis, Staphylococcus aureus, Asper-gillus flavus and Candida albicans, Zn (II) complex has gave an excellent antibacterial and antifungal activity [35].<smiles>Cc1ccc2ccccc2c1/C=N/c1nc[nH]n1</smiles>

Figure18. 3-Amino-1,2,4-triazole Schiff base ligand.
In the same year, Al-Osaimi A. and co-workers synthesized unsymmetrical tridentate Schiff base ligands from the reaction of 2-aminotheiophenol with three types of aldehydes derivatives Figure 19. The unsymmetrical Schiff base ligands were treated with metal ions Co (II), Fe (III) and Ni (II). These complexes were characterized by physical and chemical techniques and all these complexes were proposed as an octahedral geometry. The molar conductivity of the complexes showed non-electrolytic behavior. The antimicrobial data exhibit that all the complexes have biologically activity more than the tridentate ligand, against the bacterial strains. The free Schiff base showed no activity against fungal strains also the complexes were showed weak properties. All the metal complexes have good molluscicidal activity against snails which are more activity than the free Schiff base [36].

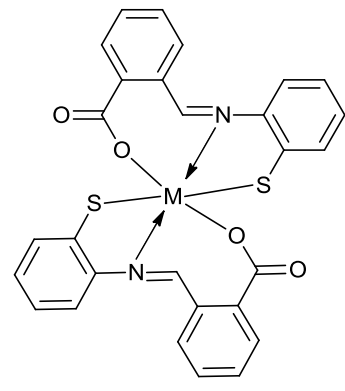

(1)

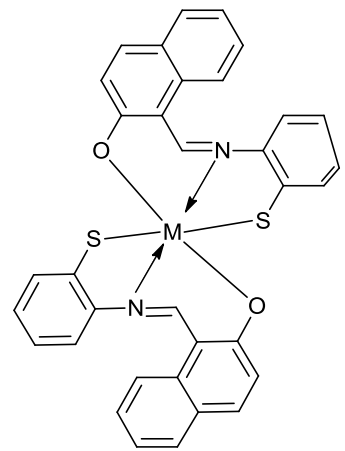

(2)

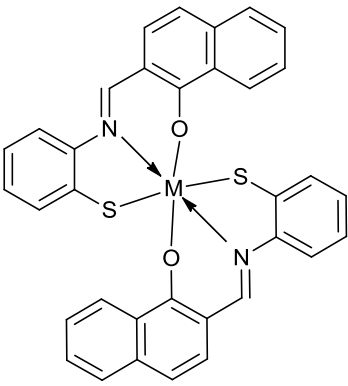

(3)

Figure 19. Chemical structures of metal complexes $(\mathrm{M}=\mathrm{Fe}(\mathrm{III}), \mathrm{Ni}(\mathrm{II})$, and $\mathrm{Co}(\mathrm{II}))(1)\left[\mathrm{M}(\mathrm{SL} 1)_{2}\right]$, (2) $\left[\mathrm{M}(\mathrm{SL} 2)_{2}\right]$, (3) $\left[\mathrm{M}(\mathrm{SL} 3)_{2}\right]$.

In the same year, Sheida E. and co-workers studied the molecular properties of five Schiff base ligands with $\mathrm{Sn}$ (IV) ion. All these ligands and complexes were investigated by density functional theory Figure 20. The theoretical calculation was shows the bond angles, bond distances and optimized structures of Sn (IV) complexes. The geometry of the complex was monomer type and it's coordinate with chelating ligand through deprotonated phenolic and imine group. Also, the calculation was included IR frequencies, HOMO, LUMO energy gap, dipole moment, Mulliken charges and Hartree-Fock energies. The bacteriological activity of Schiff base with all complexes were tested against Staphylococcus aureus and Escherichia coli by growth-inhibiting zone and was gave a good activity against these bacteria [37].

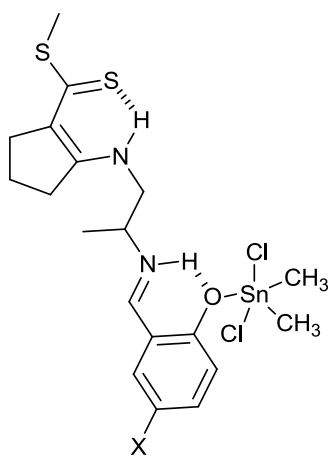

$\mathrm{X}=\mathrm{H}, \mathrm{OMe}, \mathrm{Br}, \mathrm{Cl}, \mathrm{NO}_{2}$

Figure 20. The structure of Sn (IV) complexes.

In the same year, Mohamed G. and co-workers synthsized the Schiff base ligand from 2hydroxybenzaldehyde and reacted with diffrent transition metal ions such as $\mathrm{Cr}$ (III), Mn (II), Fe (III), Co (II), Ni (II), $\mathrm{Cu}$ (II), $\mathrm{Zn}$ (II) and $\mathrm{Cd}$ (II), Figure 21. These complexes were characterized via many physical techniques, chemical techniques and molecular docking methods. The Schiff base ligand was bonded with the metal ion through the deprotonated hydroxiyle and imine 


\title{
Al-Nahrain Journal of Science
}

\author{
ANJS, Vol.24 (1), March, 2021, pp. 1-10
}

group and all the complexes have the octahedral geometry. The optimized structures was performed by DFT calculation and used to calculate the, bond lengths, energy gap of ligand and complexes as well as the calculation of quantum chemical parameters for tetradentate Schiff base and thier metal complexes. The biolagical activities of the

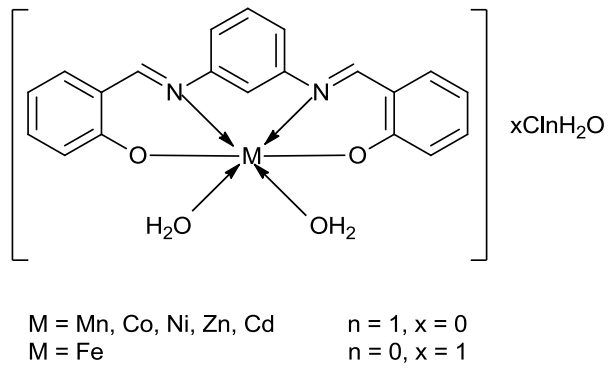

(a) ligand and complexes was studied against bacterial and fungi by inhibition zones such as Escherichia coli and Staphy lococcus aureu. A comparative study between ligand and complexes was shown that most complexes exhibit higher antibacterial and antifungal effect against bacterial species than the free ligand [38].<smiles>COc1ccccc1/C=N/c1cccc(/C=N/c2ccccc2O)c1</smiles>

(b)

Figure 21. Chemical structure of tetradentate Schiff base and there metal complexes.

In 2020, Sakhare D. and co-workers described the synthesis of novel Schiff base derivative from thiosemicarbazide and reacted with divalent nickel and copper ion according to 1:1 (M: L) mole ratio, Figure 22. The ligand act as chelating through the azomethine group and sulfur atom and was characterized by physical and chemical analysis. These complexes show a good to moderate antibacterial activity through measuring the inhibition zone against Enterobactera erogenes, and Bacillus cereus [39].

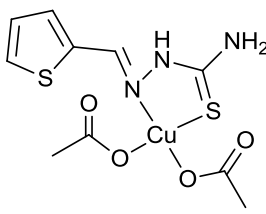

(1)

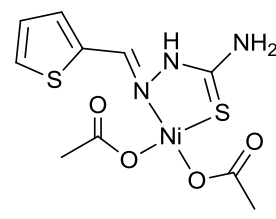

(2)
Figure 22. Structure of thiosemicarbazone complexes.

In the same year, Ommenya F. and co-workers prepared the new Schiff base ligand derived from the 5chlorosalicylaldehyde and was characterized with their complexes via different spectroscopy techniques, Figure 23. This ligand was giving octahedral geometry when different types of complexes such as $\mathrm{Co}$ (II), $\mathrm{Cu}$ (II), $\mathrm{Ni}$ (II), Mn (II), and Zn (II). The molar conductivity analysis of all complexes was given a non-electrolytic behavior. The ligand and their complexes were studied invitro to assessing their antibacterial, against Gram-positive (Bacillus subtilis and Staphylococcus Typhi) and Gramnegative bacteria (Escherichia coli and Pseudomonas aeruginosa) by the diffusion method, all these complexes were gave a good activities against these bacteria [40].

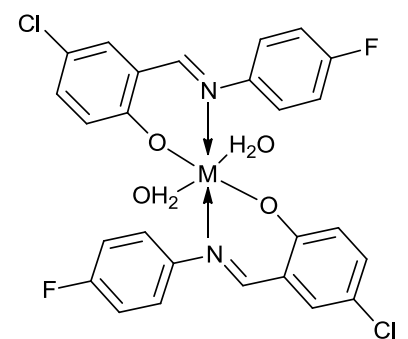

$\mathrm{M}=\mathrm{Co}$ (II), $\mathrm{Cu}$ (II), Ni (II), Mn (II) and Zn (II)

Figure 23. structure of Schiff base complexes.

In the same year, Venkittapuram P. and co-workers synthesized Schiff base ligand from reaction of 1,2diamino ethane with creatinine by condensation process Figure 24. The ligand was coordinated with $\mathrm{Co}$ (II) and $\mathrm{Cu}$ (II) ions, and these complexes were characterized by analytical and spectroscopic measurements. The spectroscopic data were suggested the tetrahedral geometry for these complexes with 1:1 (M:L) stoichiometry. The DFT method was used in computational study for these complexes and was used to calculate the chemical reactivity, geometry of the complex and dipole moment. The ligand and complexes were tested against the gram positive bacterial (Staphylococcus aureus and Bacillus subtilis) and gram negative bacteria (Escherichia coli, Pseudomonas aeruginosa). Also screened against the fungal (Aspergillus niger and Candida albicans). The $\mathrm{Co}$ (II) and $\mathrm{Cu}$ (II) complexes were exhibit a good antibacterial and antifungal activity if it compared with the free ligand [41]. 


\title{
Al-Nahrain Journal of Science
}

\author{
ANJS, Vol.24 (1), March, 2021, pp. 1-10
}

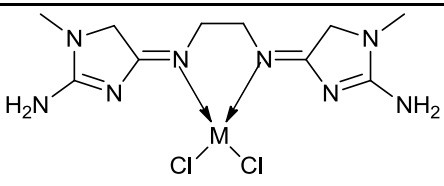

Where $\mathrm{M}=\mathrm{Co}$ (II) and $\mathrm{Cu}$ (II)

Figure 24. Geometry of the two complexes Co (II) and $\mathrm{Cu}$ (II).

In the same year, Nizam A. and co-workers reported the synthesis of tetradentate Schiff base ligand with Pd (II) complexes, and characterized by spectroscopic analysis. The computational study was calculated by timedependent DFT in gas-phase then compared with the experimental results to predict the geometry of complex. The bonding with Pd (II) ion was occur through the phenolic group and the imine nitrogen, the geometry of complex will be square planar, Figure 25. Anticancer activity of the complex against HCT1116 was tested and gave good results due to soft nitrogen metal with the availability of $\mathrm{d}$ electrons. The square planar structure was improved palladium (II) complex in the pharmacological process [42].

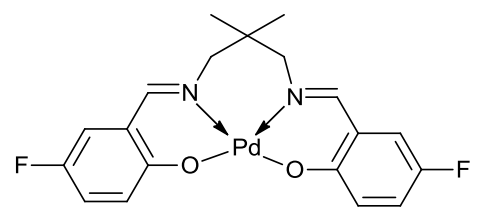

Figure 25. Chemical geometry of Pd (II) complex.

\section{Conclusions}

Schiff base ligand and there complexes are one of the most important compounds which are used in different applications due to their chemical versatility, vast synthetic way to different molecular structures and usually easy to prepare. Many Schiff base ligands and there complexes were used as an active medicinal agents. The present paper was focus on some important Schiff base ligands with their complexes which have microbial activity against different types of bacterial and fungal.

\section{References}

[1] Siddappa K. and Mayana N. S., "Synthesis, Spectroscopic Characterization, and Biological Evaluation Studies of 5-Bromo-3-(((hydroxy-2methylquinolin-7-yl)methylene)hydrazono)indolin-2one and Its Metal (II) Complexes", Bioinorg. Chem. Appl., 2014, 1-11, 2014.

[2] Wozniczka M.; Sutradhar M.; Pombeiro A.; Swiatek M.; Pajak M.; Gadek J.; Chmiela M.; Gonciarz W.; Pasternak B. and Kufelnicki A. "Equilibria in Aqueous Cobalt(II)-Reduced Schiff Base N-(2hydroxybenzyl)alanine System: Chemical Characterization, Kinetic Analysis, Antimicrobial and Cytotoxic Properties", Molecules, 25(15), 22-43, 2020.

[3] Ibrahim F. M.; Jassim A. H. and Muhyedeen B. R. J., "Synthesis and AB initio study of biologically important thioamide". LAP LAMBERT Academic Publishing, 2018.

[4] Gavalyan V. B., "Synthesis and characterization of new chitosan-based Schiff base compounds", Carbohydr. Polym., 145, 37-47, 2016.

[5] Boceiri N.; Benabdallah T. and M. Hadj, "Synthesis and Characterization of a Novel Series of Amphiphilic Mercapto-1,2,4-Triazole Schiff Base Ligands : Investigation of their Behavior in Hydro-Organic Solutions", J. Surfactants Deterg. 19, 583-597, 2016.

[6] Ibrahim F. M., "Polyether Hexadentate Schiff Base Ligand with Trivalent Chromium, Iron, Cobalt Ions", J. Al-Nahrain Univ. Sci., 20(4), pp.1-6, 2017.

[7] Bassanetti I.; Atzeri C.; Tinonin D. A. and Marchiò L., "Silver (I) and Thioether-bis(pyrazolyl)methane Ligands: The Correlation between Ligand Functionalization and Coordination Polymer Architecture", Cryst. Growth Des., 16(6), 3543-3552, 2016.

[8] Jaros S. W.; Guedes Da Silva M. F. C.; Florek M.; Smoleński P.; Pombeiro A. J. L. and Kirillov A. M., "Silver(I) 1,3,5-Triaza-7-phosphaadamantane Coordination Polymers Driven by Substituted Glutarate and Malonate Building Blocks: Self-Assembly Synthesis, Structural Features, and Antimicrobial Properties", Inorg. Chem., 55(12), 5886-5894, 2016.

[9] Al-Zoubi W.; Al-Hamdani A.; Ahmed S. and Ko Y. G., "Synthesis, characterization, and biological activity of Schiff bases metal complexes", J. Phys. Org. Chem., 31(2), 2018.

[10] Dhokale N. T.; Karale B. K. and Nagawade A. V., "Synthesis, Characterization and Antibacterial Studies on Mn (II) and Fe (II) Complexes of N, O Donor Salicyloyl Pyrazole Oxime Schiff Bases", Oriental Journal of Chemistry, 3(1), 165-172, 2017.

[11] Chai L.; Huang J.; Zhang J. and Li Y., "Two 1-D and 2-D cobalt (II) complexes: synthesis, crystal structures, spectroscopic and electrochemical properties", Journal of Coordination Chemistry, 68(7), 1224-1237, 2015.

[12] Phenol M.; Kırca B. K.; Tarı G. Ö.; Kaştaş Ç. A. and Odabaşoğlu M., "Crystal structure, spectral characterization, molecular modeling studies and structural effects of the proton transfer process for (E)-5-methoxy-2-[(3,4-dimethylphenylimino) methyl]phenol", Journal of Chemistry and Chemical Engineering, 36(2), 265-278, 2017.

[13] Sidir I.; Sidir Y. G.; Berber H. and Demiray F., "Emerging ground and excited state dipole moments and external electric field effect on electronic structure. A solvatochromism and theoretical study on 2-((phenylimino)methyl)phenol derivatives", J. Mol. Liq., 206, 56-67, 2015.

[14] Kostova I. and Saso L., "Advances in Research of Schiff-Base Metal Complexes as Potent Antioxidants", Curr Med Chem., 20(36), 4609-4632, 2013. 


\title{
Al-Nahrain Journal of Science
}

\author{
ANJS, Vol.24 (1), March, 2021, pp. 1-10
}

[15] Agrawal S., "Drug -Metal Complexes in Research A Review”, Ultra Scientist, 27(2), 113-116, 2015. d

[16] Hadi M. A. and Kareem I. K., "Synthesis and characterization of some transition metal complexes with new azo- schiff base ligand 3,4-bis(((1E,2E)-2((2-((4-((Z)-(3-Hydroxyphenyl)Diazenyl)Naphthalen1-yl)amino)ethyl) imino)-1,2-Diphenylethylidene) Amino)Phenyl)(phenyl)Methanone", Egypt. J. Chem., 63(1), 301-313, 2020.

[17] Modi J. A.; Desai K. R. and Lokhandwala S. R., "Synthesis of some new 1,2,4-triazoles, their Mannich and Schiff bases and evaluation of their antimicrobial activities", European Journal of Medicinal Chemistry, 3(3), 1875-1885, 2014.

[18] Saddam Hossain Md.; Pijush Kanti Roy, Roushown Ali and Zakaria C. M., "Selected Pharmacological Applications of 1st Row Transition Metal Complexes: A review", Clinical Medicine Research, 6(6), 177-191, 2017.

[19] Elena Pahont; Ilies D.-C.; Shova S.; Oprean C.; Paunescu V. and Olaru O. T., "Synthesis, Characterization, Antimicrobial and Antiproliferative Activity Evaluation of $\mathrm{Cu}(\mathrm{II}), \mathrm{Co}(\mathrm{II}), \mathrm{Zn}(\mathrm{II}), \mathrm{Ni}(\mathrm{II})$ and $\mathrm{Pt}(\mathrm{II})$ Complexes with Isoniazid-Derived Compound", Molecules, 22(650), 1-17, 2017.

[20] Fonkui T. Y.; Ikhile M. I.; Ndinteh D. T. and Njobeh P. B., "Microbial activity of some heterocyclic schiff bases and metal complexes: A review", Trop. J. Pharm. Res., 17(12), 2507-2518, 2018.

[21] Al-Masoudi N. A.; Aziz N. and Mohammed A., "Synthesis and In vitro anti-HIV activity of some new Schiff base ligands derived from 5-Amino-4phenyl-4H-1,2,4-triazole-3- thiol and their metal complexes", Phosphorus Sulfur Silicon Relat Elem., 184, 2891-2901, 2009.

[22] Abdel-Rahman L.; El-Khatib R.; Nassr L., A. Abudief, and F. Lashin, "Spectrochimica Acta Part A : Molecular and Biomolecular Spectroscopy antifungal and DNA interaction of few high spin Fe (II) Schiff base amino acid complexes", Spectrochim. Acta Part A Mol. Biomol. Spectrosc., 111, 266-276, 2013.

[23] Abu-dief A. M. and Mohamed I. A., "ScienceDirect A review on versatile applications of transition metal complexes incorporating Schiff bases", Beni-Suef Univ. J. Basic Appl. Sci., 4(2), pp.119-133, 2015.

[24] Sharma S. J. M., Chauhan K., Srivastava R. K., Singh S. V., Srivastava K. and E. Al, "Design and synthesis of a new class of 4-Aminoquinolinyl- and 9Anilinoacridinyl Schiff base hydrazones as potent antimalarial agents", Chem Biol Drug Des., 84, 175$181,2014$.

[25] Jha A., Murthy Y. L. N. and Durga G., "Synthesis, characterization and bioactivity of transition metal complexes of new 3-methyl-5-mercapto-4-triazole schiff bases", Res. J. Pharm. Biol. Chem. Sci., 6(1), pp.1306-1314, 2015.

[26] Kulandaisamy A. and Palanimurugan A., "Studies on schiff base transition metal complexes derived from benzil, p- Studies on schiff base transition metal complexes derived from benzil", J. Chem. Pharm. Res., 7(10), pp.111-119, 2015.

[27] Hasan R., Hossain M. A., Salam A. and Uddin M. N., "acid: Synthesis, Characterization and microbial evaluation", Integr. Med. Res., 10, 766-773, 2015.

[28] De Fátima Â., de P. Pereira C., Olímpio C. R. S. D. G., de Freitas Oliveira B. G., Franco L. L. and C. da Silva P. H., "Schiff bases and their metal complexes as urease inhibitors - A brief review", J. Adv. Res., 13, 113-126, 2018.

[29] Kuete V., Karaosmanog O. and Sivas H., "Anticancer Activities of African Medicinal Spices and Vegetables, Academic press" 2017.

[30] Kareem M. A., "Synthesis, Characterization and Antimicrobial Studies of TransitionMetal Complexes with Azo Ligand derivative from 4Aminoantipyrine", First National Conference of Sciences and Literatures, C, 83-91, 2017.

[31] Reiss A., Amzoiu M. E., Cioatera N., Da buleanu I. and Rotaru P., "New metal (II) complexes with ceftazidime Schiff base", J Therm Anal Calorim, 131, 2017.

[32] Zhang L. W., Liu L. Z., Wang F. and Dong W. K., "Unprecedented fluorescent dinuclear CoII and ZnII coordination compounds with a symmetric bis(salamo)-like tetraoxime", Molecules, 23(5), 2018.

[33] Yildirim N. and Yildiz M., "DFT calculation, biological activity, anion sensing studies and crystal structure of (E) -4-chloro-2- [(pyridin-2-ylimino) methyl ] phenol", J. Serb. Chem. Soc., 83(6), 707721, 2018.

[34] Yıldız M., Karpuza Ö., Tuğrul C., Bahadır Z., B. Hakan, Neslihan D., Nuray D. and Hüseyin Ünver Y., "Synthesis, biological activity, DNA binding and anion sensors, molecular structure and quantum chemical studies of a novel bidentate Schiff base derived from 3, 5-bis (triflouromethyl) aniline and salicylaldehyde", J. Mol. Struct., 1094, 148-160, 2015.

[35] Abdelsalam M. M.; "Green Synthesis, Spectral, Thermal Characterization and Biological Activity of Schiff base Ligand Derived from 3-amino-1, 2, 4triazol and its Metal Complexes", 8(3), 2-11, 2019.

[36] Al-Osaimi A. M.; Mannoubi I. and Azabin S., "Synthesis, Molluscicidaland Antimicrobial Potentialities of Iron Triad Mononuclear Metal Complexes Incorporating Tridentate Asymmetrical Schiff Base Ligands Containing Soft Sulfur Coordinating Atom", Asian J. Pharm. Clin. Res., 13(2), 103-113, 2019.

[37] Esmaielzadeh1 S. and Sharif-Mohammadi M., "Tin(IV) Schiff bass complexes: Synthsis, thermodinamic and anti bactrial invistigation, experemental and theoriyical studies", Bull. Chem. Soc. Ethiop, 33(1), 77-90, 2019. 


\section{$\mathrm{Al}$-Nahrain Journal of Science}

ANJS, Vol.24 (1), March, 2021, pp. 1-10

[38] Mohamed G. G.; Mahmoud W. H.; Diab M. A.; ElSonbati A. Z. and Abbas S. Y., "Synthesis, characterization, theoretical study and biological activity of Schiff base nanomaterial analogues", J. Mol. Struct., 1181, 645-659, 2019.

[39] Sarker D.; Hossen F. and Haque M., "Synthesis, Characterization, Thermal Analysis and Antibacterial Activity of $\mathrm{Cu}$ (II) and $\mathrm{Ni}$ (II) Complexes with Thiosemicarbazone Derived from", 5(2), 15-25, 2020

[40] Ommenya F. K.; Nyawade E. A.; Andala D. M. and Kinyua J., "Synthesis, Characterization and Antibacterial Activity of Schiff Base, 4-Chloro-2$\{($ E)-[(4-Fluorophenyl)imino]methyl $\}$ phenol Metal (II) Complexes", J. Chem., 2020, 2020.

[41] Venkittapuram P.; Dhandapani M.; Suyambulingam J. and Subramanian C., "Synthesis, characterization, thermal, theoretical and antimicrobial studies of Schiff base ligand and its $\mathrm{Co}$ (II) and $\mathrm{Cu}$ (II) complexes", J. Serbian Chem. Soc., 85(2), 215-225, 2020.

[42] Ahmad N.; Anouar E. H.; Tajuddin A. M.; Ramasamy K.; Yamin B. M. and Bahron H., "Synthesis, characterization, quantum chemical calculations and anticancer activity of a Schiff base NNOO chelate ligand and Pd(II) complex", PLOS One, 15(4), 1-17, 2020. 